One-step microfluidics production of enzyme-loaded liposomes for the treatment of inflammatory diseases

\title{
Costa, Clarinda
}

2021-03

Costa , C , Liu , Z, Simões , S, Rebelo Correia , A M , Rahikkala , A T A, Seitsonen , J , Ruokolainen , J , Aguiar- Ricardo , A , Santos , H A \& Corvo , M L 2021 , ' One-step microfluidics production of enzyme-loaded liposomes for the treatment of inflammatory diseases ' , Colloids and Surfaces B: Biointerfaces , vol. 199 , 111556 . https://doi.org/10.1016/j.colsurfb.2020.11155

http://hdl.handle.net/10138/328659

https://doi.org/10.1016/j.colsurfb.2020.111556

acceptedVersion

Downloaded from Helda, University of Helsinki institutional repository.

This is an electronic reprint of the original article.

This reprint may differ from the original in pagination and typographic detail.

Please cite the original version. 


\section{Journal Pre-proof}

One-step microfluidics production of enzyme-loaded liposomes for the treatment of inflammatory diseases

Clarinda Costa (Formal analysis) (Visualization) (Writing - original draft) (Investigation) (Methodology) (Conceptualization) (Validation), Zehua Liu (Methodology) (Conceptualization) (Validation), Sandra Simõ es (Investigation) (Methodology) (Conceptualization) (Validation), Alexandra Correia (Investigation), Antti Rahikkala (Investigation), Jani Seitsonen (Investigation) (Resources), Janne Ruokolainen (Investigation) (Resources), Ana Aguiar-Ricardo (Conceptualization) (Validation) (Supervision) (Resources) (Writing - review and editing), Hélder A. Santos (Conceptualization) (Validation) (Supervision) (Resources) (Writing - review and editing), M. Luísa Corvo (Conceptualization) (Validation) (Supervision) (Resources) (Writing - review and editing)

PII: S0927-7765(20)30913-9

DOI: https://doi.org/10.1016/j.colsurfb.2020.111556

Reference: COLSUB 111556

To appear in: Colloids and Surfaces B: Biointerfaces

Received Date: 13 October 2020

Revised Date: 24 December 2020

Accepted Date: 26 December 2020

Please cite this article as: Costa C, Liu Z, Simõ es S, Correia A, Rahikkala A, Seitsonen J, Ruokolainen J, Aguiar-Ricardo A, Santos HA, Corvo ML, One-step microfluidics production of enzyme-loaded liposomes for the treatment of inflammatory diseases, Colloids and Surfaces B: Biointerfaces (2020), doi: https://doi.org/10.1016/j.colsurfb.2020.111556 
This is a PDF file of an article that has undergone enhancements after acceptance, such as the addition of a cover page and metadata, and formatting for readability, but it is not yet the definitive version of record. This version will undergo additional copyediting, typesetting and review before it is published in its final form, but we are providing this version to give early visibility of the article. Please note that, during the production process, errors may be discovered which could affect the content, and all legal disclaimers that apply to the journal pertain.

(C) 2020 Published by Elsevier. 


\section{Stastitical summary:}

Total number of words: 7395

Total number of tables: 1

Total number of images: 5

One-step microfluidics production of enzyme-loaded liposomes for the treatment of inflammatory diseases

Clarinda Costa, ${ }^{a b c}$ Zehua Liu, ${ }^{a}$ Sandra Simões, ${ }^{d}$ Alexandra Correia, ${ }^{a}$ Antti Rahikkala, ${ }^{a}$ Jani Seitsonen, ${ }^{e}$ Janne Ruokolainen, ${ }^{e}$ Ana Aguiar-Ricardo ${ }^{b *}$, Hélder A. Santos, ${ }^{a f}$ M. Luísa $\operatorname{Corvo}^{c *}$

${ }^{\text {a }}$ Drug Research Program, Division of Pharmaceutical Chemistry and Technology, Faculty of Pharmacy, University of Helsinki, Helsinki FI-00014, Finland

E-mails: cid.costa@campus.fct.unl.pt; zehua.liu@helsinki.fi; alexandra.correia@helsinki.fi; antti.rahikkala@helsinki.fi; helder.santos@helsinki.fi

b LAQV, REQUIMTE, Departamento de Química, Faculdade de Ciências e Tecnologia , Universidade Nova de Lisboa, 2829-516 Caparica, Portugal

E-mail: air@fct.unl.pt

c Instituto de Investigação do Medicamento (iMed.ULisboa), Faculdade de Farmácia, Universidade de Lisboa, Avenida Professor Gama Pinto, 1649-003 Lisboa, Portugal

E-mail:1corvo@ff.ulisboa.pt

d Nanostructured Systems for Overcoming Biological Barriers group of iMed.ULisboa, Research Institute for Medicines, Faculdade de Farmácia, Universidade de Lisboa, Lisboa, Portugal

E-mail: ssimoes@ff.ulisboa.pt,

e Nanomicroscopy center, Aalto University, Aalto 00076, Finland

E-mail: jani.seitsonen@aalto.fi; janne.ruokolainen@ aalto.fi

${ }^{\mathrm{f}}$ Helsinki Institute of Life Science (HiLIFE), University of Helsinki, Helsinki FI-00014, F inland

E-mail: helder.santos@helsinki.fi 
*Correspondent authors: 1corvo@ff.ulisboa.pt air@fct.unl.pt

\section{Graphical abstract}

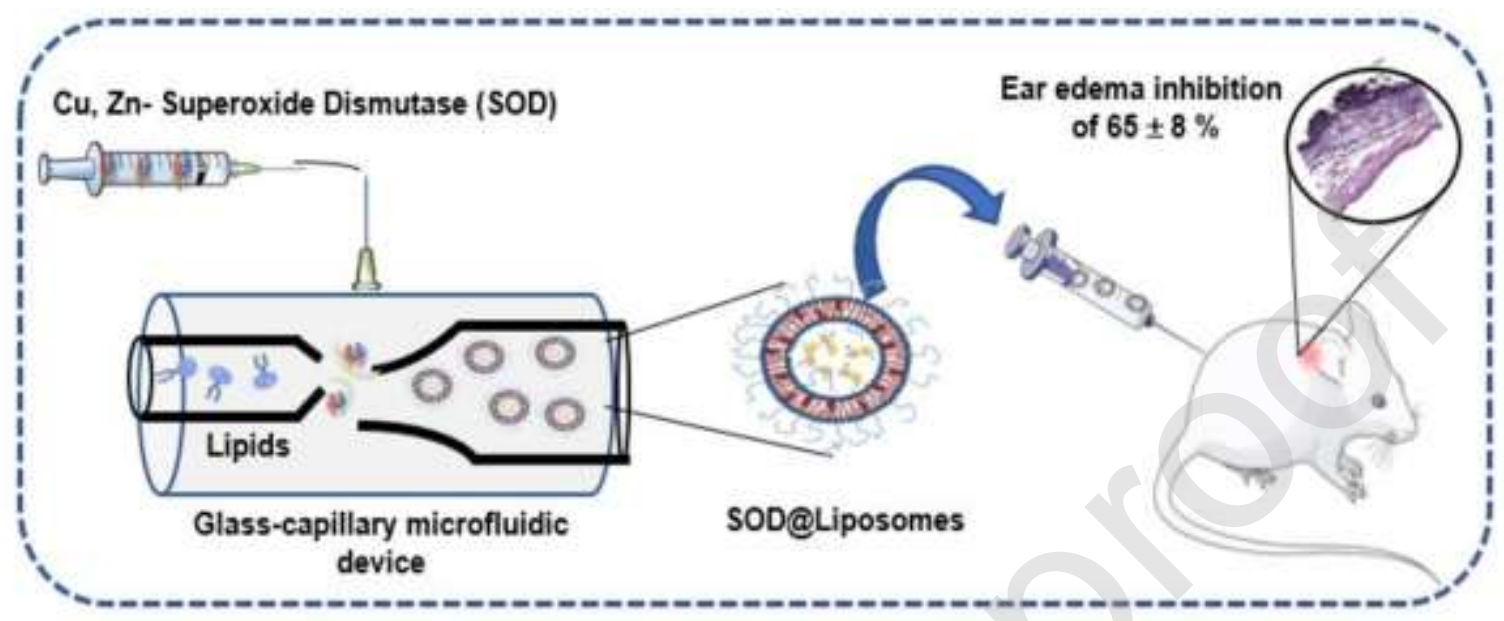

\section{Highlights}

- A glass-capillary microfluidic device is used for enzyme encapsulation in liposomes

- The enzyme (SOD) retains its enzymatic activity after encapsulation

- SOD-loaded liposomes (SOD@Lip) present an effective anti-inflammatory property

- The usefulness of systemic SOD to treat local inflammation was confirmed

\section{Abstract}

The biopharmaceuticals market is constantly growing. Despite their advantages over the conventional drugs, biopharmaceuticals have short biological half-lifes, which can be increased using liposomes. However, the common bulk methods to produce biopharmaceuticals-loaded liposomes result in lost of encapsulation efficiency (E.E.), resulting in an expensive process. Herein, the encapsulation of a therapeutic enzyme in liposomes is proposed, using a glass-capillary microfluidic technique. $\mathrm{Cu}, \mathrm{Zn}$ - Superoxide dismutase (SOD) is successfully encapsulated into liposomes (SOD@Liposomes). SOD@Liposomes with a mean size of $135 \pm 41 \mathrm{~nm}$, a polydispersity index of $0.13 \pm 0.01$, an E.E. of $59 \pm 6 \%$ and an enzyme activity of $82 \pm 3 \%$ are obtained. In vivo experiments 
show, through an ear edema model, that SOD@Liposomes administered by the intravenous route enable an edema inhibition of $65 \% \pm 8 \%$, over the $20 \% \pm 13 \%$ of SOD in its free form. The histopathological analyses show a higher inflammatory cell accumulation on the ear treated with SOD in its free form, than treated with SOD@Liposomes. Overall, this work highlights the potential of microfluidics for the production of enzyme-loaded liposomes with high encapsulation efficiency, with the intrinsic advantages of the low time-consuming and easily upscaling microfluidic assembly method.

Keywords: $\mathrm{Cu}, \mathrm{Zn}$ - Superoxide dismutase; liposomes; inflammation; microfluidics; ROS

\section{Introduction}

Biopharmaceutical drugs, such as nucleic acids, monoclonal antibodies and therapeutic enzymes, are one of the fastest growing areas on the pharmaceutical industry [1]. Comparing with the synthetic drugs, biopharmaceuticals exhibits higher activity, selectivity and lower side effects [2]. However, biopharmaceuticals can present low oral bioavailability, instability in biological fluids and short biological half-times, leading to a deficient systemic delivery and requiring high doses to obtain an efficient therapeutic effect $[3,4]$. Moreover, depending on the route of administration, biopharmaceuticals can suffer degradation and low absorption $[5,6]$. These issues can be easily overcome when a suitable drug delivery system (DDS) is developed to a targeted and efficient transport of the biopharmaceuticals [7]. Liposomes, introduced for the first time by Bangham and co-worker [8] at the beginning of the 1960s, have been widely used on the pharmaceutical field [9-11]. Liposomes are able to carry both hydrophobic and hydrophilic active compounds in the lipidic bilayer and into the inner aqueous core, respectively, enhancing the blood residence time and the targeted delivery of 
the drugs [12-14]. For this reason, the application of liposomes as a versatile drug delivery system has increased over the last decades. For example, the encapsulation of biopharmaceuticals in liposomes leads to a modification in their pharmacokinetics and pharmacodynamics, improving their therapeutic activity [11]. Mokhtarieh et al. have reported that the encapsulation of siRNA in liposomes prevented it from the RNase degradation and elimination [15]. Another example is related with the $\mathrm{Cu}, \mathrm{Zn}$-Superoxide dismutase (SOD). SOD is an enzyme with a molecular weight of $32.5 \mathrm{kDa}$ that catalyzes the dismutation of anion superoxide radical in molecular oxygen and hydrogen peroxide. This enzyme is widely used on the treatment of reactive oxygen species (ROS)-mediated diseases, such as rheumatoid arthritis [16,17], inflammation [18,19] and ischemia-reperfusion injury $[18,19]$. However, the administration of SOD without a drug delivery system presents some disadvantages, such as the short half-life in the bloodstream ( $6 \mathrm{~min}$ in rats and $25 \mathrm{~min}$ in humans) [20,21], low accumulation in affected areas and rapid renal filtration [16]. Previous studies have reported the importance of the use of PEGylated liposomes as a carrier for SOD on the improvement of the enzyme biodistribution and its therapeutic effect in inflammatory processes, increasing its half-life up to $20 \mathrm{~h}$ [17,22,23]. In addition, the presence of PEG on the surface of the liposomes plays an important role on the administration of SOD-loaded liposomes, since it avoids the liposomes opsonization by the mononuclear phagocyte system (MPS) [24,25]. For this reason, the application of liposomes in the delivery of biopharmaceuticals has aroused a particular interest. The common bulk techniques for the production of liposomes rely on the thin-film hydration $[23,26]$, reverse phase evaporation [27,28] and ethanol injection [29]. Apart from the fact that post-processing steps, such as high pressure extrusion [30], are required to obtain a better control of size and polydispersity index (PdI), these techniques also involve the use of organic solvents often resulting in an enzyme inactivation during the process [31].

Moreover, the saturation curve of the enzyme concentration in the inner aqueous space and the technical compromise between the efficient encapsulation (E.E.) and the small size of the liposomes [23], make reaching a stable and E.E. of macromolecules in liposomes challenging [32]. Previous works have demonstrated that bulk methods result in enzymeloaded liposomes with low E.E. for small liposomes due to the sizing of the liposomes by extrusion, but with an efficient therapeutic effect. These works also related the effect of the 
sizing on the E.E, where it is notorious that the lesser the need of sizing (less extrusion processes) of the liposomes, the higher the E.E. of SOD. For example, Corvo et al. obtained an E.E of 8-21\%, $27 \pm 3 \%$ and $20 \%$ for SOD-loaded liposomes with $110 \pm 10 \mathrm{~nm}$ [23], 230 $\pm 90 \mathrm{~nm}$ [17] and $200 \pm 20 \mathrm{~nm}$ [22], respectively. York-Duran et al. obtained an E.E. of 3.0 $\pm 0.8 \%$ for catalase-loaded liposomes size between 110 and $120 \mathrm{~nm}$ [33]. Moreover, Morozova et al. reported an E.E. about $25 \%$ for enzyme-loaded liposomes with $218 \pm 6 \mathrm{~nm}$ [34].

Microfluidics is an emerging technology, which enables the manipulation of fluids (in nanoliters scale) in micrometer channels [35]. Over the last years, this technique has gained a special attention on the biomedical field, since it can be widely used for the production of polymeric nano/micro-particles, due to the advantages of being a continuous process when compared to the current bulk methods [36]. High batch-to-batch reproducibility, higher process control, easy scalability and no requirement of postprocessing steps are some of the advantages that microfluidics can offer $[37,38]$. Polydimethylsiloxane (PDMS), glass and silica, are the common material used on the manufacturing of microfluidic devices [39-41]. Upon contact with organic solvents, acids or bases, PDMS can swell or be degraded [42] and, due to its hydrophobic nature, the polymers tend to aggregate on the walls of the device [43]. To overcome these main drawbacks, borosilicate glass capillary can be used. Glass is cheap, inert to chemical solvents and does not swell in contact with solvents $[36,42]$. The application of the microfluidics for the liposomes production, specifically glass-capillary microfluidic devices, has been reported [44-46]. Through a nanoprecipitation method $[47,48]$ it is possible to produce liposomes in a single step process $[49,50]$.

In this work, we propose the production of enzyme-loaded liposomes (SOD@Liposomes) with similar physico-chemical properties of the commonly produced ones by bulk methods, but with higher efficiency encapsulation and process yield, using a glass-capillary microfluidic device (Scheme 1). We aimed to obtain a continuous and simple one-step method that offers a scalable, reproducible, time and cost efficient and a high throughput production of SOD-loaded PEGylated liposomes for therapeutic purposes. 


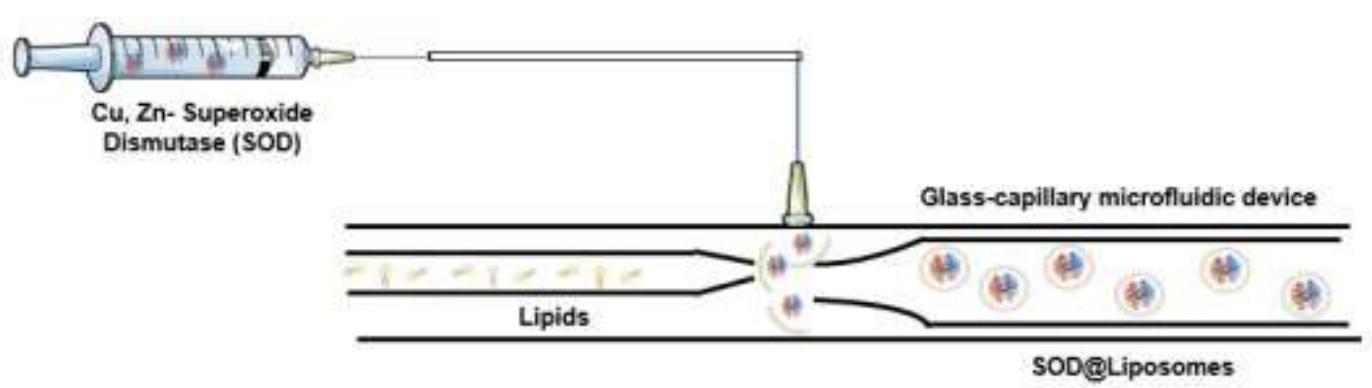

Scheme 1: Schematic representation of the microfluidic process on the encapsulation of SOD in PEGylated liposomes (not to scale). Lipids and cholesterol were dissolved in ethanol (inner phase), whereas SOD was dissolved in a saline citric buffer at $\mathrm{pH} 6$ (outer phase).Through the nanoprecipitation technique, the lipids self-assembled, enclosing the enzyme in the aqueous inner phase (SOD@Liposomes).SOD@Liposomes were then collected by the collecting capillary.

\section{Materials and methods}

\subsection{Materials}

Egg-phosphatidylcholine (E-PC) and distearoylphosphatidylethanolaminepoly(ethyleneglycol) 2000 (DSPE-PEG 2000 ) were obtained from Lipoid (Germany). Cholesterol (Chol), bovine erythrocytes $\mathrm{Cu}, \mathrm{Zn}$-superoxide dismutase, 300 kU (SOD), 2-(4-(2hydroxyethyl) piperazin-1-yl) ethanesulfonic acid (HEPES), citric acid, anthralin and sodium chloride were purchased from Sigma-Aldrich (USA). Hank's balanced salt solution (HBSS) and phosphate buffer saline (PBS) were purchased from Life Technologies (USA). Triton ${ }^{\circledR}$ X-100 was purchased from Merck Millipore (Germany). Dulbecco's Modified Eagle's medium (DMEM), L-glutamine, non-essential amino acids, penicillin (100 $\left.\mathrm{IU} \mathrm{mL}^{-1}\right)$ and streptomycin $\left(100 \mathrm{mg} \mathrm{mL}^{-1}\right)$, ethylenediamine tetraacetic acid (EDTA) and trypsin-EDTA were purchased from HyClone (USA). Human colon carcinoma (Caco-2) and the human colorectal adenocarcinoma modified with methotrexate (HT29-MTX) cells were purchased from ATCC (USA). CellTiter-Glo ${ }^{\circledR}$ assay reagent was purchased from Promega Corporation (USA).

\subsection{Methods}

\subsubsection{Preparation of liposomes and SOD-loaded liposomes (SOD@Liposomes)}


The liposomes and SOD-loaded liposomes were prepared by the nanoprecipitation method, [47] using a modified co-flow microfluidic glass-capillary device. Briefly, a borosilicate glass capillary (inner capillary with a diameter of $100 \mu \mathrm{m}$ ) was placed in front of another glass capillary with an inner diameter of $120 \mu \mathrm{m}$ (collecting capillary), slightly deviated. Both were inserted into a glass capillary (outer capillary) with an inner diameter of $1000 \mu \mathrm{m}$. Then, a mixture of E-PC, DSPE-PEG 2000 and Chol (molar ratio 1.85:0.15:1, respectively) was dissolved in ethanol, in a total lipid concentration of $48.0 \mu \mathrm{mol} \mathrm{mL} \mathrm{m}^{-1}$ and injected in the inner phase. Alike, a saline citric acid buffer $(145 \mathrm{mM}$ of $\mathrm{NaCl}, 10 \mathrm{mM}$ of Citric Acid, $\mathrm{pH}$ 6.0) without and with SOD, in a final concentration of $75 \mu \mathrm{g} \mathrm{mL}^{-1}$, was injected in the outer phase. Both streams were injected with flow rates of $25 \mathrm{~mL} \mathrm{~h}^{-1}$ and a flow rate ratio (FRR) of 1. The SOD@Liposomes from the collecting capillary and non-encapsulated enzyme was separated from the liposomes by ultracentrifugation twice (Optima L-80, XP Ultracentrifuge, Beckman Coulter, CA, USA), at $135000 \mathrm{~g}$ at $4{ }^{\circ} \mathrm{C}$ for $2 \mathrm{~h}$. Then, the SOD@Liposomes pellet was re-suspended in a saline citric acid buffer solution at $\mathrm{pH}$ 6.0. The experiment was performed in triplicate.

\subsubsection{Characterization of liposomes and SOD@Liposomes}

The liposomal formulations were characterized in terms of their morphology and phospholipid concentration. SOD@Liposomes were also characterized in terms of protein concentration and enzyme activity. Liposome size, determined as Z-average, the PdI, as a measure of the particle size distribution that can range from 0 (monodisperse) and 1.0 (polydisperse), and the surface charge (zeta $(\zeta)$-potential), were determined using Zetasizer Nano ZS (Malvern Instruments Ltd., UK). The structure of the SOD@Liposomes was confirmed using cryo-transmission electron microscope (Cryo-TEM, JEOL JEM-3200FSC, JEOL, Tokyo, Japan). Briefly, prior to use, vitrified specimens were prepared using an automated FEI Vitrobot device, and Quantifoil 3.5/1 holey carbon copper grids with a hole size of $3.5 \mu \mathrm{m}$. Then, an aliquot of liposomal suspension was applied on the grid and it was blotted twice for $5 \mathrm{sec}$ and then vitrified in a 1:1 mixture of liquid ethane and propane at -180 ${ }^{\circ} \mathrm{C}$. The grids with the vitrified liposomes were kept in liquid nitrogen temperature and then cryo-transfered to the microscope. Imaging was carried out using a field emission cryo-TEM (JEOL JEM-3200FSC), operating at $200 \mathrm{kV}$. Images were taken in the bright field mode and 
using zero loss energy filtering (omega type) with a slit width of $20 \mathrm{eV}$. Micrographs were recorded using a Gatan Ultrascan 4000 CCD camera (Gatan Inc., Pleasanton, CA, USA). The specimen temperature was maintained at $-187^{\circ} \mathrm{C}$ during the imaging. The images were treated using Gatan Microscopy Suite Software (Gatan Inc).

The concentration of phospholipids was determined by the Rouser's method [51]. The enzyme was quantified with a modified Lowry's method [52], where liposomes were previously disrupted with $2 \%$ (v/v) Triton ${ }^{\circledR} \mathrm{X}-100$ and $20 \%$ (v/v) of sodium dodecylsulphate (SDS) [53]. The E.E was calculated as follows (Eq. 1):

$$
\text { E.E. }(\%)=\frac{\left(\frac{\text { Prot }}{\text { Lip }}\right)_{f}}{\left(\frac{\text { Prot }}{\text { Lip }}\right)_{i}} \times 100
$$

where, the $\left(\frac{\text { Prot }}{\text { Lip }}\right)_{i}$ is the initial SOD-to-lipid ratio and $\left(\frac{\text { Prot }}{\text { Lip }}\right)_{f}$ is the SOD-to-lipid ratio after the removal of the non-encapsulated enzyme.

The SOD enzymatic activity from SOD@Liposomes was evaluated using the SOD assay kit (19160-1KT-F, Sigma-Aldrich), where liposomes were previously disrupted with 2 $\%(\mathrm{v} / \mathrm{v})$ Triton $^{\circledR} \mathrm{X}-100$ and $20 \%(\mathrm{v} / \mathrm{v})$ of SDS.

\subsubsection{Cell lines and cell culture conditions}

HT29-MTX (passage \#32) and Caco-2 (passages \#35-40) were separately cultured in a 75 $\mathrm{cm}^{2}$ culture flask in DMEM containing $10 \%$ of fetal bovine serum (FBS), $1 \%(\mathrm{v} / \mathrm{v})$ of Lglutamine, $1 \%(\mathrm{v} / \mathrm{v})$ of penicillin and streptomycin and $1 \%(\mathrm{v} / \mathrm{v})$ of non-essential amino acids. The cells were left to grow under $37^{\circ} \mathrm{C}$, in $5 \%$ of $\mathrm{CO}_{2}$ and relative humidity of $95 \%$. The cell culture medium was changed every other day. Sub-culturing was performed using trypsin-PBS-EDTA when confluency reached $80 \%$.

\subsubsection{In vitro cytotoxic studies}

The cell viability studies were carried out using CellTiter-Glo ${ }^{\circledR}$ assay reagent (previously diluted with HBSS-HEPES buffer at $\mathrm{pH} 7.4$, in a ratio of $1: 1(\mathrm{v} / \mathrm{v}))$. Briefly, $5 \times 10^{4}$ cells of Caco-2 and HT29-MTX cell lines were individually seeded in 96-well plates (Corning Inc., USA), and left to attach for $24 \mathrm{~h}$. Afterwards, the medium was discarded, and the cells were washed with HBSS-HEPES buffer at $\mathrm{pH}$ 7.4. Then, $100 \mu \mathrm{L}$ of liposomes with a SOD 
concentration ranging from 2.5 to $15 \mu \mathrm{g} \mathrm{mL} \mathrm{m}^{-1}$ were added to the cells. The cells were incubated at $6 \mathrm{~h}$ or $24 \mathrm{~h}$, under $37^{\circ} \mathrm{C}$. After the incubation time, cells were washed twice with fresh HBSS-HEPES buffer, and $100 \mu \mathrm{L}$ of CellTiter-Glo ${ }^{\circledR}$ was added. The plates were lightly shaken for $2 \mathrm{~min}$. HBSS-HEPES and 1\% (v/v) Triton ${ }^{\circledR} \mathrm{X}-100$ solutions were used as positive and negative controls, respectively. The luminescence values were measured using a Varioskan Flash Multimode Reader (Thermo Fisher Scientific, USA). All the experiments were performed at least in triplicate.

\subsubsection{Animal experiments}

NMRI female mice (6 weeks of age) were purchased from Charles River (France). The animals were used after one week for acclimatization on the laboratory environment $(21 \pm 1$ ${ }^{\circ} \mathrm{C}$ and $50 \pm 4 \%$ of relative humidity; $12 \mathrm{~h}$ day/night cycle and water and food ad libitum). All animal experiments were conducted according to the animal welfare organ of the Faculty of Pharmacy, Universidade de Lisboa, approved by the competent national authority Direção Geral de Alimentação e Veterinária (DGAV) and in accordance with the EU Directive (2010/63/UE) and Portuguese laws (DL 113/2013, 2880/2015, 260/2016, and 1/2019).

\subsubsection{Anthralin induced ear edema model}

The anthralin induced ear edema model was performed according to Lange et al.[54], modified by Ascenso et al. [55]. When applied onto the ear skin, anthralin provokes an ear swelling, induced by ROS in the skin. The animals were anesthetized, and the thickness of both ears was measured using a Mitutoyo ${ }^{\circledR}$ dial gage. Six groups of animals $(n=5)$ were tested: (i) $7.3 \mu \mathrm{g}$ of SOD $(180 \mu \mathrm{L})$ of SOD@Liposomes were administered intravenously (i.v.); (ii) $7.3 \mu \mathrm{g}$ of SOD $(180 \mu \mathrm{L})$ of SOD previously dissolved in citrate buffer (free SOD (i.v.)) were administered i.v.; (iii) $7.3 \mu \mathrm{g}$ of SOD $(180 \mu \mathrm{L})$ of SOD@Liposomes were administered intraperitoneally (i.p.); (iv) $7.3 \mu \mathrm{g}$ of SOD $(180 \mu \mathrm{L})$ of SOD previously dissolved in citrate buffer (free SOD (i.p.)), administrated by i.p.; (v) $10 \mu \mathrm{L}$ of $0.1 \%$ betamethasone solution was applied on the right ear (positive control); and (vi) one group of animals received no treatment. Treatments were administered $1 \mathrm{~h}$ before the challenge for groups from (i) to (iv). Group (v) received the application $1 \mathrm{~h}$ after the challenge. The challenge, $10 \mu \mathrm{L}$ of anthralin $(10 \mathrm{mM})$ suspended in a mixture of $70 \%$ ethanol and olive oil 
(4:1), was topically applied on the pinna of both ears in all groups. Mice were kept in individual cages and, $24 \mathrm{~h}$ after the challenge, the resulting edema was determined through the measurement of the ears thickness (in triplicate). The percentage of the edema inhibition was determined by the comparison between the thickness of non-treated ears (negative control) and ear thickness of the treated animals.

\subsubsection{Histopathological analysis}

After the experiments, mice were euthanized with prior anesthesia with isoflurane and the ear pinna were collected. Then, the ears were fixed in formalin and submitted to histopathological analysis. Hematoxylin and eosin stain were used.

\subsubsection{Statistical analysis}

All results are expressed as mean \pm standard deviation (S.D.), except the animal experiments which are expressed as mean \pm standard error of the mean (SEM). To analyze the data, analysis of variance (ANOVA) followed by Bonferroni post test (GraphPadPrism, GraphPad software Inc., CA, USA) was used. The level of significance was set at the probabilities of $* \mathrm{p}<0.05, * * \mathrm{p}<0.01$ and $* * * \mathrm{p}<0.001$.

\section{Results and Discussion}

\subsection{Characterization of Liposomes and SOD@Liposomes}

The encapsulation of SOD in liposomes was achieved through a nanoprecipitation method [47]. In fact, into the glass-capillary microfluidic device, upon contact with the saline citrate buffer, the polarity of the lipid-based ethanolic solution increased. Lipids self-assembled, enclosing the buffered SOD (SOD@Liposomes). Previous works have demonstrated that, due to the physicochemical properties of the SOD and liposomes, SOD is exclusively encapsulated in the inner aqueous compartment $[17,23,56]$. In the case of empty liposomes (control), a buffered aqueous core was enclosed in spherical vesicles [37,57]. The obtained SOD@Liposomes were characterized and the results are shown in Table 1. SOD@Liposomes presented an average size of $135 \pm 41 \mathrm{~nm}$, and a PdI of $0.128 \pm 0.010$, whereas liposomes without SOD presented an average size of $171 \pm 14 \mathrm{~nm}$ and a PdI of 0.140 
\pm 0.016 . Even though it would be expected that SOD@Liposomes presented higher diameter values, the difference between the size of SOD@Liposomes and empty liposomes is within the variability with the variability among the batches. Both formulations presented a near zero $\zeta$ - potential value, as expected for PEG coated liposomes. The E.E. for SOD@Liposomes was $59 \pm 6 \%$ (Table 1). Previous works, using bulk methods for encapsulation of SOD in liposomes, have reported different and lower E.E.. Corvo et al. reported an E.E. of $21 \pm 2 \%$ for SOD@Liposomes (lipid concentration of $48 \mu \mathrm{mol} \mathrm{mL}^{-1}$ ) with a mean size of $110 \pm 10 \mathrm{~nm}$ [23], whereas Rengel et al. reported for a similar nanosytem an E.E. of about $13 \%$ for a mean size of $90 \pm 60 \mathrm{~nm}$ [58]. Simões et al. also reported SOD@Liposomes with a mean size of $149 \pm 9 \mathrm{~nm}$ and an E.E. of $34 \pm 2 \%$ [59] and, more recently, Marcelino et al. obtained enzyme-loaded liposomes with an E.E. of $9 \pm 2 \%$ for a mean size of $140 \pm 20 \mathrm{~nm}$ [60]. Previous works have also demonstrated that neutral SOD@Liposomes formulations are stable over the time, at $4^{\circ} \mathrm{C}$ [20,61-63].

An important consideration in this system is the retention of SOD enzymatic activity after the microfluidic process. Although the mixing time is fast, in this method ethanol is used as solvent in the inner phase, which might represent a threat for the enzyme activity. In this way, the SOD activity was evaluated and an enzymatic activity of $82 \pm 3 \%$ was observed (previous works reported a activity between $90-95 \%$ for bulk methods $[20,23,58]$ ), attesting that the microfluidic technique does not compromise the activity of the enzyme [64]. As such, the production of SOD@Liposomes through the glass-capillary microfluidic process represents a notable improvement on the encapsulation of the enzyme over the formulations (with similar physico-chemical properties) produced by bulk process.

Table 1: Physicochemical characterization of Liposomes, E.E. and retained enzymatic activity of SOD@Liposomes.

\begin{tabular}{ccccccc}
\hline & Size & PdI & $\begin{array}{c}\zeta- \\
\text { potential } \\
{[\mathbf{m V}]}\end{array}$ & $\begin{array}{c}(\text { Prot/Lip)f } \\
{[\mu \mathrm{\mu g} / \mu \mathrm{mol}]}\end{array}$ & $\begin{array}{c}\text { E.E. } \\
{[\%]}\end{array}$ & $\begin{array}{c}\text { Ret. Act. } \\
{[\%]^{*}}\end{array}$ \\
& {$[\mathbf{n m}]$} & & & & & \\
\hline SOD@Liposomes & $135 \pm 41$ & $0.13 \pm 0.01$ & $-0.6 \pm 0.2$ & $0.92 \pm 0.10$ & $59 \pm 6$ & $82 \pm 3$ \\
Liposomes & $171 \pm 14$ & $0.14 \pm 0.02$ & $0.4 \pm 0.8$ & - & - & - \\
\hline
\end{tabular}

The results are expressed as mean \pm S.D $(n=3)$ PdI: Polydispersity index 
(Prot/Lip)f: Final enzyme to lipid ratio considering the final lipid concentration value. Ret. Act.: Retained enzymatic activity. ${ }^{*} \mathrm{n}=$ two independent batches.

In order to confirm the structure of the SOD@Liposomes, a Cryo-TEM analysis was performed (Figure 1). The image shows a thin single-wall structure enclosing a vesicle with a mean size of $158 \pm 7 \mathrm{~nm}$, determined by Gatan Microscopy Suite software.

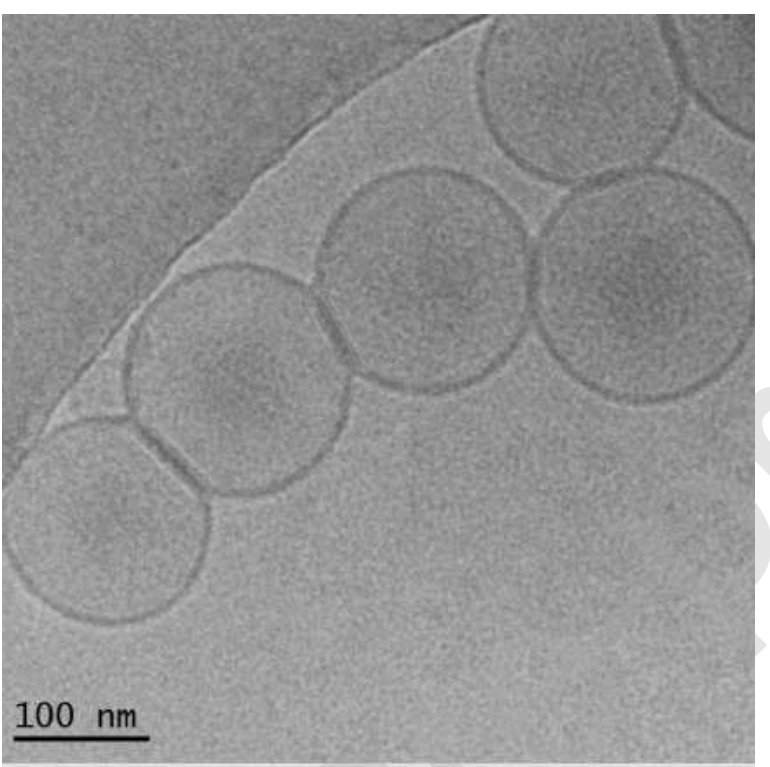

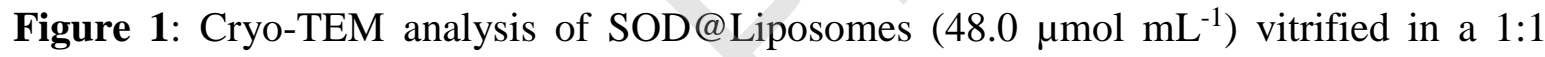
mixture of liquid ethane and propane at $-180{ }^{\circ} \mathrm{C}$.

\subsection{In vitro cytotoxic studies}

Cytotoxicity tests were performed using the CellTiter-Glo luminescence assay. Briefly, the Caco-2 and HT29-MTX cell lines (used in this work as a cellular model) were exposed to various concentrations of enzyme-loaded liposomes and empty liposomes, ranging from an equivalent concentration of the enzyme from $2.5 \mu \mathrm{g} \mathrm{mL}^{-1}$ to $15 \mu \mathrm{g} \mathrm{mL} \mathrm{m}^{-1}$, for $6 \mathrm{~h}$ and $24 \mathrm{~h}$. After $6 \mathrm{~h}$, both cell lines presented higher viability for SOD@Liposomes than for empty liposomes, $13 \pm 9 \%$ and $14 \pm 4 \%$, for Caco-2 and HT29-MTX cell lines, respectively (Figure 2). This was an expected result due to the antioxidant capacity of SOD. Since cancer cells can produce higher levels of ROS, leading to an oxidative stress, a consequent cell apoptosis might occur [65]. As such, upon action of SOD, the amount of ROS decrease, 
resulting also in a reduction of the oxidative stress. Therefore, it is expected an increase in the cell viability [66]. After 24 h, HT29-MTX cells presented a slight decrease of the cell viability at higher concentration. This can be related with the toxicity of the liposomes at high concentrations, as also obverved before by Adamczak et al. [67]. For a lower concentration of neutral liposomes, a decrease of $\sim 25 \%$ was observed. Since the viability remained above $79 \%$, the liposomes are considered non-toxic, according to the guidelines from the regulatory authorities [68]. Moreover, SOD@liposomes have already been used for longer treatment periods and no toxicity was observed [69]. Therefore, next the in vivo studies were pursued.

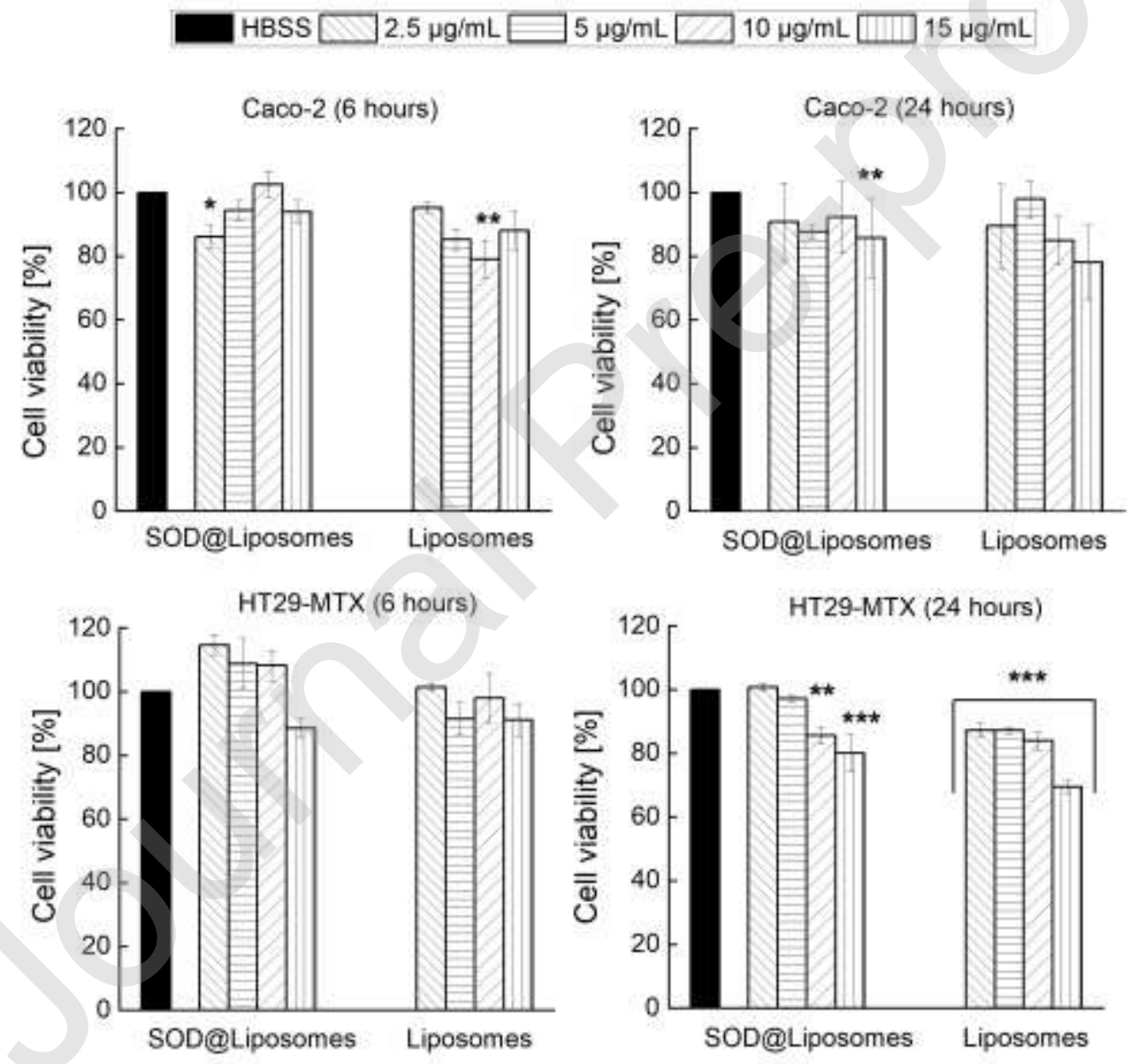

Figure 2: HT29-MTX and Caco-2 cells lines viability when exposed to different concentrations of SOD@Liposomes and empty liposomes, after $6 \mathrm{~h}$ and $24 \mathrm{~h}$ of incubation 
at $37^{\circ} \mathrm{C}$. All the data were compared to the negative control (HBSS-HEPES at pH 7.4). The level of significance was set at the probabilities of $* \mathrm{p}<0.05, * * \mathrm{p}<0.01$ and $* * * \mathrm{p}<0.001$. The results are expressed as mean \pm S.D. $(n=3)$.

\subsection{In vivo activity}

The animal experiments using the anthralin ear edema model were conducted for 24 $h$ to evaluate the anti-inflammatory effect of SOD formulated in liposomes, based on its antioxidant properties. Among the animal models available for the evaluation of antiinflammatory agents, the anthralin (1,8- dihydroxy-9-anthrone)-induced ear swelling is an important tool to evaluate the relationship between anthralin-induced oxidative stress and ear swelling. The ear swelling assay was performed according to the method described by Lange et al. [54] also tested for topical antioxidants application [55,70]. In fact, oxidative stress plays an important role in chemically induced inflammation as occurring with anthralin contact with the skin, responsible for the generation of ROS within the skin. Betamethasone was reported to reduce mice ear edema in this cutaneous inflammation model $[55,70,71]$ and was used in this assay as a positive control to validate the model. The experimental inflammation evoked by the application of anthralin (epidermal hyperplasia and inflammatory cell infiltration) is remarkably reduced by betamethasone topical application. The work of Lange and co-workers presented systemic antioxidant administration to provide an opportunity to treat the oxidative stress generated at the site of anthralin application that can change the expression of dermal chemokines responsible for the recruitment of inflammatory cells [54]. In this work we have confirmed the usefulness of systemic SOD to treat local inflammation. The well-known biological activity of SOD has a bell-shape curve. It is known that doses ranging from 30 and $400 \mu \mathrm{g} \mathrm{kg}^{-1}$ are in the high activity profile [21]. Thus, we administered $180 \mu \mathrm{L}$ (7.3 $\mu \mathrm{g})$ of SOD@Liposomes and SOD dissolved in the citrate buffer (free SOD), equivalent to a dose of $300 \mu \mathrm{g} \mathrm{kg}^{-1}$ in each mouse. The i.v. and i.p. administrations were performed $1 \mathrm{~h}$ before the application of the challenge, since the inflammation onset occurs $24 \mathrm{~h}$ after the challenge. Figure 3 shows the edema inhibition percentage for each group. As expectable, it is possible to observe that SOD@Liposomes presented a higher edema inhibition $(65 \% \pm 8 \%$ ), compared to SOD in its free form (20\% $\pm 13 \%$ ). This is due to the liposome's ability to improve the half-life of the enzyme, avoiding 
the fast SOD clearance $[17,20]$ and the presence of PEG that can also increase the liposomes circulation in the bloodstream over $24 \mathrm{~h}$, improving the therapeutic effect of SOD@Liposomes [23]. Moreover, the improvement of the therapeutic effect of the SOD@Liposomes is also related with the enhanced permeability and retention effect. This effect allows the extravasation and the accumulation of the PEGylated liposomes in the inflamed tissues, enabling a more efficient enzyme delivery [72,73].

The administration of SOD@Liposomes by different routes of administration was also assessed. Figure 3 shows a significant higher edema inhibition $(* p<0.05)$ for SOD@Liposomes administered i.v. over the i.p. route. SOD@Liposomes (i.v.) showed an edema inhibition of $65 \% \pm 8 \%$, whereas SOD@Liposomes (i.p.) showed an edema inhibition of $33 \% \pm 13 \%$. Such difference is related with the different biodistribution of SOD@Liposomes, regarding the administration route. Previous studies have demonstrated that nanoparticles administrated by i.p. tend to accumulate in the local tissues in the abdominal cavity [74]. In addition, the peritoneal-blood barrier can limit the transport of the liposomes from the peritoneal cavity into the bloodstream [75]. Allen et al. also observed an increase of the half-life of the liposomes administered by i.p. of $9 \mathrm{~h}$, contrasting with the halflife of $20.4 \mathrm{~h}$ from the liposomes administered by i.v. [76] As such, by i.v. administration, the distribution of the liposomes throughout the bloodstream is more effective than by i.p., supporting the observed values. Both in vitro and in vivo studies highlight the superiority of the developed liposomal formulation over SOD in its free form. 


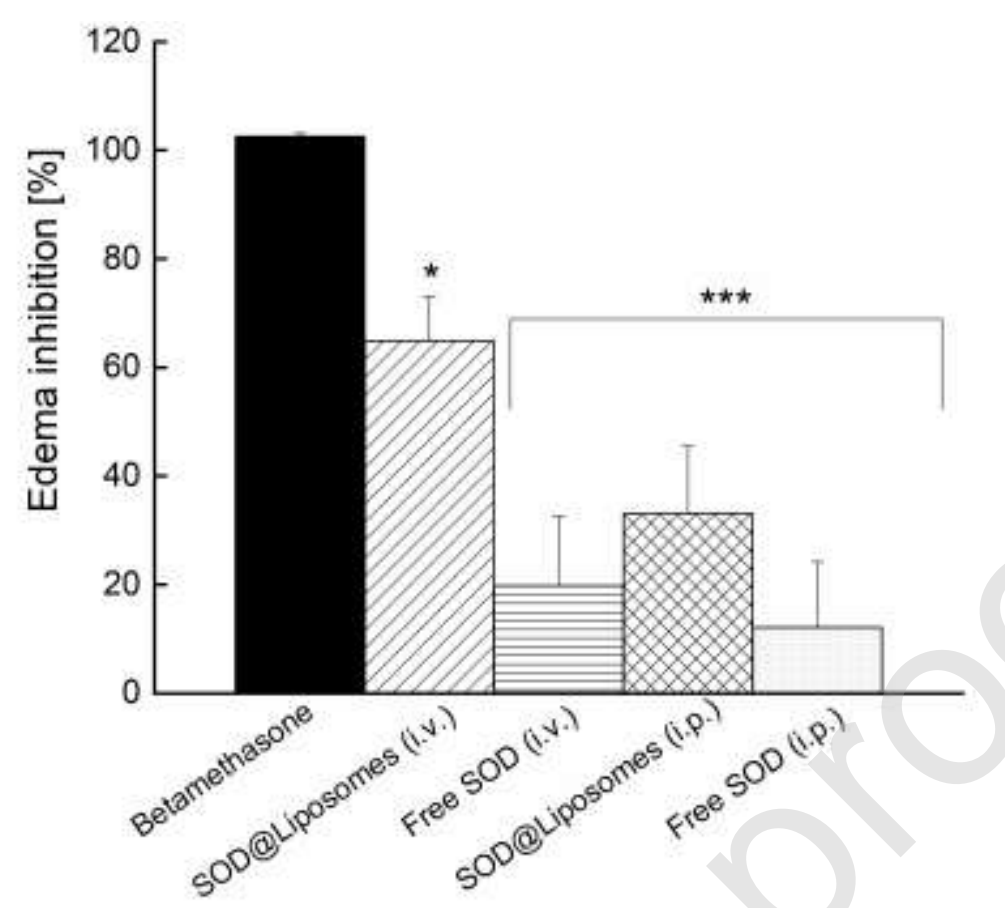

Figure 3: Effect of the treatment with i.v. administration of SOD@Liposomes (SOD-Liposomes (i.v.)), i.v. administration of SOD solution (Free SOD (i.v.)), i.p. administration of SOD@Liposomes (SOD- Liposomes (i.p.)), i.p. administration of SOD solution (Free SOD (i.p.)), topical application of betamethasone (positive control), $24 \mathrm{~h}$ after mice ear challenge with $10 \mathrm{mM}$ of anthralin, expressed as percentage of ear edema inhibition. Each result represents the mean and SEM $(\mathrm{n}=5),{ }^{*} p<0.05$ and $* * * p<0.001$.

Histological analyses of the ears, collected after $24 \mathrm{~h}$ of challenge application, confirmed the superior efficacy of the encapsulated SOD in inhibiting the edema formation, in comparison to the SOD administered in the free form (Figure 4). The negative control (anthralin applied on the ear, without treatment) showed mild acanthosis (increase of the cell layer), papillomatosis (external overgrowth of epidermis with elongation of dermal papillae) and epidermal hyperkeratosis (increase of the thickness of the cornified layer) (Figure 4A). The free SOD (i.v.) treated animals (Figure 4B) also presented a mixed focal inflammation (acanthosis, papillomatosis and hyperkeratosis), although the papillomatosis was not so evident. In addition, an epidermal reaction was also observed. Ears from animals treated with SOD@Liposomes (i.v.) (Figure 4C) showed a focal ulceration of epidermis with underlying mixed inflammation. These observations are in accordance with the previous results from the percentage of the edema inhibition. A higher inflammation was observed for those mice that 
were treated with SOD solution, without liposomes. The images from SOD@Liposomes (i.p.) treated animals (Figure 4D) showed only a slight focal epidermal hyperkeratosis and no other significant changes. Regarding the free SOD (i.p.) treated mice (Figure 4E), a mild epidermal hyperkeratosis was observed, corrobarationg the need of liposomes as a drug delivery system that enhances the therapeutic effect of the enzyme. Finally, as expected, the positive control (betamethasone) did not exhibit cellular infiltration or edema (Figure 4F). The measurement of the ear edema pointed to the superiority of the i.v administration of SOD@Liposomes over the i.p. administration. However, the cellular events assessed by histological analysis do not corroborate these findings. In any case, the superiority of encapsulated SOD over free SOD to inhibit edema formation was confirmed.

A

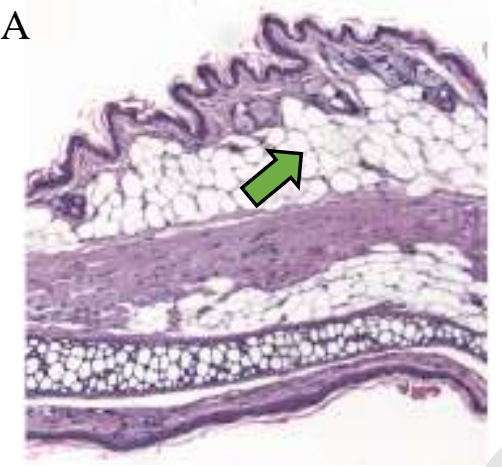

D

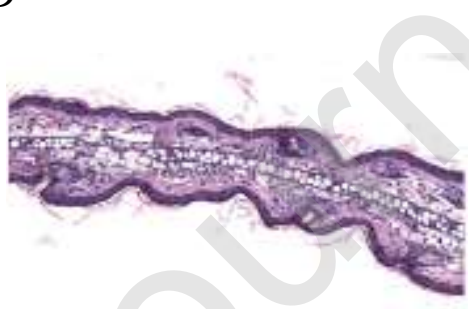

B

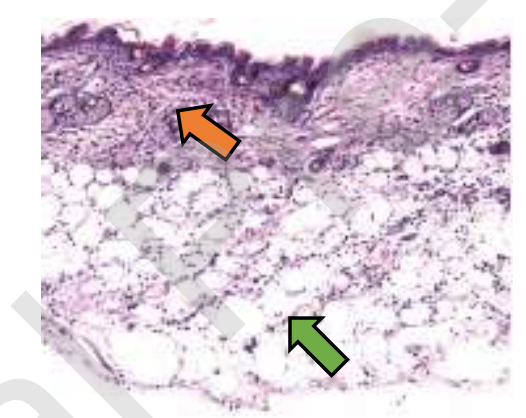

$\mathrm{E}$

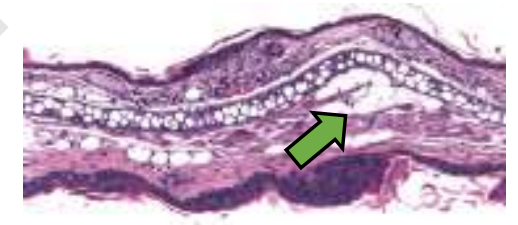

C

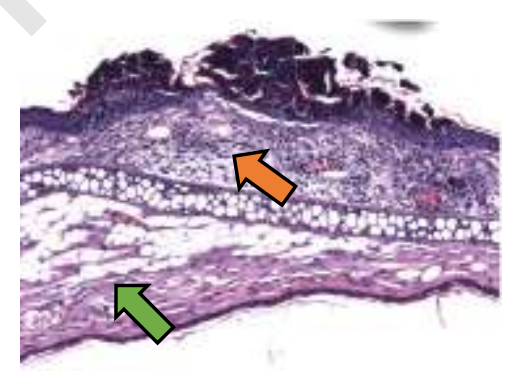

F

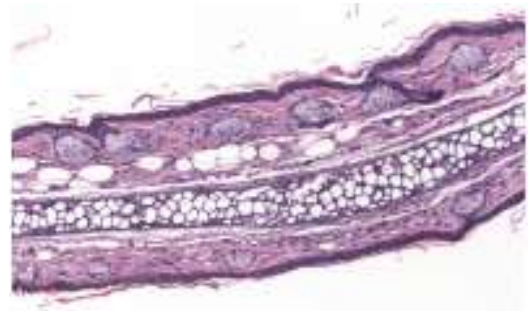

Figure 4: Representative microphotographs of longitudinal sections $(100 \times)$ of the mouse ear pinna from (A) negative control; (B) free SOD (i.v.); (C) SOD@liposomes (i.v.); (D) SOD@Liposomes (i.p.); (E) free SOD (i.p.); and (F) positive control (betamethasone), after $24 \mathrm{~h}$ of challenge application. The edema is highlighted by the orange arrows, whereas the inflammatory cell infiltration is highlighted by the green arrows. 


\section{Conclusions}

In this work, the microfluidic technique was used to encapsulate SOD in PEGylated liposomes (SOD@Liposomes). In this manner, SOD was efficiently encapsulated (59 $\pm 6 \%$ ), showing higher E.E. than SOD@Liposomes with similar physicochemical properties from conventional processes. Although the process requires the use of an organic solvent, the SOD@Liposomes retains the enzymatic activity $(82 \pm 3 \%)$. This work highlights the potential of the microfluidic technique to overcome the high loss of enzyme associated to the common batch production of liposomal formulations, which makes the process cheaper. The produced nanosystems also showed high cytocompatibility in the cells tested. In vivo experiments to test the anti-inflammatory properties of SOD@Liposomes showed the inhibition of $65 \pm 8 \%$ for animals treated with SOD@Liposomes administered i.v. The histopathological studies also showed the effectiveness of the administration of the SOD@Liposomes, compared to the SOD administered on its free form, as a result of the decreased infiltration of inflammatory cells. Overall, microfluidics showed to be a suitable and efficient technique to encapsulate SOD into liposomes, which represent a promising approach to encapsulate therapeutic enzymes in liposomes anti-inflammatory applications in vivo.

\section{Credit Author Statement}

Clarinda Costa: Formal analysis; Visualization; Writing - Original Draft Clarinda Costa, Sandra Simões, Alexandra Correia, Antti Rahikkala: Investigation Clarinda Costa, Zehua Liu, Sandra Simões: Methodology Clarinda Costa, Zehua Liu, Sandra Simões, Hélder A. Santos, Ana Aguiar-Ricardo, M.L. Corvo: Conceptualization, Validation

Jani Seitsonen, Janne Ruokolainen: Investigation, Resources Ana Aguiar-Ricardo, Hélder A. Santos, M.L. Corvo: Supervision; Resources, Writing review \& editing.

\section{Conflict of interest}

Authors declare no conflicts of interest.

\section{Declaration of interests}


$\bigotimes$ The authors declare that they have no known competing financial interests or personal relationships that could have appeared to influence the work reported in this paper.

\section{Acknowledgments}

C. Costa and A. Aguiar-Ricardo are grateful for the financial support of the Associate Laboratory for Green Chemistry-LAQV, which is financed by national funds from FCT/MCTES (UIDB/50006/2020). C. Costa also acknowledges the FCT/MCTES for the grant PD/BD/142880/2018 and for the travel grant. M.L. Corvo acknowledges the financial support from Research Institute for Medicines (iMed.ULisboa), Faculty of Pharmacy,

Universidade de Lisboa, Lisbon, Portugal, which is supported in part by UID/DTP/04138/2020 from FCT/MCTES, Portugal. H.A. Santos acknowledges financial support from the HiLIFE Research Funds and the Sigrid Jusélius Foundation.

\section{References}

[1] M. Bjelošević, A. Zvonar Pobirk, O. Planinšek, P. Ahlin Grabnar, Excipients in freeze-dried biopharmaceuticals: Contributions toward formulation stability and lyophilisation cycle optimisation, Int. J. Pharm. 576 (2020).

doi:10.1016/j.ijpharm.2020.119029.

[2] M. Kesik-Brodacka, Progress in biopharmaceutical development, Biotechnol. Appl. Biochem. 65 (2018) 306-322. doi:10.1002/bab.1617.

[3] J. Swaminathan, C. Ehrhardt, Liposomal delivery of proteins and peptides, Expert Opin. Drug Deliv. 9 (2012) 1489-1503. doi:10.1517/17425247.2012.735658.

[4] M.L. Van Slooten, O. Boerman, K. Romøren, E. Kedar, D.J.A. Crommelin, G. Storm, Liposomes as sustained release system for human interferon- $\gamma$ :

Biopharmaceutical aspects, Biochim. Biophys. Acta - Mol. Cell Biol. Lipids. 1530 (2001) 134-145. doi:10.1016/S1388-1981(00)00174-8.

[5] S. Jun Cao, S. Xu, H. Ming Wang, Y. Ling, J. Dong, R. Dong Xia, X. Hong Sun, Nanoparticles: Oral Delivery for Protein and Peptide Drugs, AAPS PharmSciTech. 20 (2019) 1-11. doi:10.1208/s12249-019-1325-Z. 
[6] S. Mitragotri, P.A. Burke, R. Langer, Overcoming the challenges in administering biopharmaceuticals: formulation and delivery strategies, Nat Rev Drug Discov. 13 (2014) 655-672. doi:10.1016/j.physbeh.2017.03.040.

[7] M. Eug, M. Cruz, S. Isabel, M. Lu, B. Maria, F. Martins, Formulation of NPDDS for macromolecules, in: Drug Deliv. Nanoparticles Formul. Charact., 2009: pp. 35-49. doi:10.3109/9781420078053-4.

[8] A.D. Bangham, M.M. Standish, J.C. Watkins, Diffusion of univalent ions across the lamellae of swollen phospholipids, J. Mol. Biol. 13 (1965) 238-252. doi:10.1016/S0022-2836(65)80093-6.

[9] D. Carugo, E. Bottaro, J. Owen, E. Stride, C. Nastruzzi, Liposome production by microfluidics: Potential and limiting factors, Sci. Rep. 6 (2016) 1-15. doi:10.1038/srep25876.

[10] Y. Barenholz, Doxil® - The first FDA-approved nano-drug: Lessons learned, J. Control. Release. 160 (2012) 117-134. doi:10.1016/j.jconrel.2012.03.020.

[11] U. Bulbake, S. Doppalapudi, N. Kommineni, W. Khan, Liposomal formulations in clinical use: An updated review, Pharmaceutics. 9 (2017) 1-33. doi:10.3390/pharmaceutics9020012.

[12] J. Parmentier, M.M.M. Becker, U. Heintz, G. Fricker, Stability of liposomes containing bio-enhancers and tetraether lipids in simulated gastro-intestinal fluids, Int. J. Pharm. 405 (2011) 210-217. doi:10.1016/j.ijpharm.2010.12.005.

[13] H.M. Patel, B.E. Ryman, Oral administration of insulin by encapsulation within liposomes, FEBS Lett. 62 (1976) 10-13.

[14] G. Gregoriadis P.D. Leathwood Brenda E. Ryman, Enzyme Entrapment in Liposomes, FEBS Lett. 14 (1971) 95-99. doi:10.1016/S0076-6879(76)44019-3.

[15] A.A. Mokhtarieh, J. Lee, S. Kim, M.K. Lee, Preparation of siRNA encapsulated nanoliposomes suitable for siRNA delivery by simply discontinuous mixing, Biochim. Biophys. Acta - Biomembr. 1860 (2018) 1318-1325. doi:10.1016/j.bbamem.2018.02.027.

[16] M.E.M. Cruz, M.M. Gaspar, M.B.F. Martins, M.L. Corvo, Liposomal superoxide dismutases and their use in the treatment of experimental arthritis, Methods Enzymol. 391 (2005) 395-413. doi:10.1016/S0076-6879(05)91022-7. 
[17] M.L. Corvo, M.B. Martins, A.P. Francisco, J.G. Morais, M.E.M. Cruz, Liposomal formulations of $\mathrm{Cu}, \mathrm{Zn}$-superoxide dismutase: Physicochemical characterization and activity assessment in an inflammation model, J. Control. Release. 43 (1997) 1-8. doi:10.1016/S0168-3659(96)01473-3.

[18] V. V. Shuvaev, R.Y. Kiseleva, E. Arguiri, C.H. Villa, S. Muro, M. ChristofidouSolomidou, R. V. Stan, V.R. Muzykantov, Targeting superoxide dismutase to endothelial caveolae profoundly alleviates inflammation caused by endotoxin, $\mathrm{J}$. Control. Release. 272 (2018) 1-8. doi:10.1016/j.jconrel.2017.12.025.

[19] Q. Zhang, H. Tao, Y. Lin, Y. Hu, H. An, D. Zhang, S. Feng, H. Hu, R. Wang, X. Li, J. Zhang, A superoxide dismutase/catalase mimetic nanomedicine for targeted therapy of inflammatory bowel disease, Biomaterials. 105 (2016) 206-221. doi:10.1016/j.biomaterials.2016.08.010.

[20] M.L. Corvo, O.C. Boerman, W.J.G. Oyen, J.C.S. Jorge, M.E.M. Cruz, D.J.A. Crommelin, G. Storm, Subcutaneous administration of superoxide dismutase entrapped in long circulating liposomes: In vivo fate and therapeutic activity in an inflammation model, Pharm. Res. 17 (2000) 600-606.

doi:10.1023/A:1007577101964.

[21] G. Jadot, A. Vaille, J. Maldonado, P. Vanelle, Clinical Pharmacokinetics and Delivery of Bovine Superoxide Dismutase, Clin. Pharmacokinet. 28 (1995) 17-25. doi:10.2165/00003088-199528010-00003.

[22] M.L. Corvo, O.C. Boerman, W.J.G. Oyen, L. Van Bloois, M.E.M. Cruz, D.J.A. Crommelin, G. Storm, Intravenous administration of superoxide dismutase entrapped in long circulating liposomesII. In vivo fate in a rat model of adjuvant arthritis, Biochim. Biophys. Acta - Biomembr. 1419 (1999) 325-334. doi:10.1016/S00052736(99)00081-4.

[23] M. Luisa Corvo, J.C.S. Jorge, R. Van't Hof, M.E.M. Cruz, D.J.A. Crommelin, G. Storm, Superoxide dismutase entrapped in long-circulating liposomes: Formulation design and therapeutic activity in rat adjuvant arthritis, Biochim. Biophys. Acta Biomembr. 1564 (2002) 227-236. doi:10.1016/S0005-2736(02)00457-1.

[24] V.P. Torchilin, M.I. Papisov, Why Do Polyethylene Glycol-Coated Liposomes Circulate So Long?, J. Liposome Res. 4 (1994) 725-739. 
[25] O.K. Nag, V. Awasthi, Surface engineering of liposomes for stealth behavior, Pharmaceutics. 5 (2013) 542-569. doi:10.3390/pharmaceutics5040542.

[26] H. Elsana, T.O.B. Olusanya, J. Carr-wilkinson, S. Darby, A. Faheem, A.A. Elkordy, Evaluation of novel cationic gene based liposomes with cyclodextrin prepared by thin film hydration and microfluidic systems, Sci. Rep. 9 (2019) 1-17. doi:10.1038/s41598-019-51065-4.

[27] I. Takeuchi, N. Kishi, K. Shiokawa, H. Uchiro, K. Makino, Polyborane encapsulated liposomes prepared using $\mathrm{pH}$ gradient and reverse-phase evaporation for boron neutron capture therapy : biodistribution in tumor-bearing mice, Colloid Polym. Sci. 296 (2018) 1137-1144.

[28] D. Szoka, F.; Olson, F.; Heath, T.; Vail, W.; Mayhew, E.; Papahadjopoulos, Preparation of unilamellar liposomes of intermediate size $(0.1-0.2 \mu \mathrm{m})$ by a combination of reverse phase evaporation and extrusion through polycarbonate membranes., Biochim. Biophys. Acta - Biomembr. 601 (1980) 559-571.

[29] C. Charcosset, A. Juban, J.P. Valour, S. Urbaniak, H. Fessi, Preparation of liposomes at large scale using the ethanol injection method: Effect of scale-up and injection devices, Chem. Eng. Res. Des. 94 (2015) 508-515. doi:10.1016/j.cherd.2014.09.008.

[30] R. Ran, A.P.J. Middelberg, C.X. Zhao, Microfluidic synthesis of multifunctional liposomes for tumour targeting, Colloids Surfaces B Biointerfaces. 148 (2016) 402410. doi:10.1016/j.colsurfb.2016.09.016.

[31] A.S. Ghatorae, G. Bell, P.J. Halling, Inactivation of enzymes by organic solvents: New technique with well- defined interfacial area, Biotechnol. Bioeng. 43 (1994) 331-336. doi:10.1002/bit.260430410.

[32] D.D. Lasic, Novel applications of liposomes, Trends Biotechnol. 16 (1998) 307-321. doi:10.1016/S0167-7799(98)01220-7.

[33] M.J. York-Duran, M. Godoy-Gallardo, M.M.T. Jansman, L. Hosta-Rigau, A dualcomponent carrier with both non-enzymatic and enzymatic antioxidant activity towards ROS depletion, Biomater. Sci. 7 (2019) 4813-4826. doi:10.1039/c9bm00913b.

[34] E.A. Morozova, V. V. Kulikova, N. V. Anufrieva, A.N. Minakov, A.S. Chernov, G.B. Telegin, S. V. Revtovich, V.S. Koval, T. V. Demidkina, Methionine $\gamma$-lyase in 
enzyme prodrug therapy: An improvement of pharmacokinetic parameters of the enzyme, Int. J. Biol. Macromol. 140 (2019) 1277-1283.

doi:10.1016/j.ijbiomac.2019.08.224.

[35] Z. Liu, F. Fontana, A. Python, J.T. Hirvonen, H.A. Santos, Microfluidics for Production of Particles: Mechanism, Methodology, and Applications, Small. 16 (2020) 1-24. doi:10.1002/smll.201904673.

[36] F. Fontana, J.P. Martins, G. Torrieri, H.A. Santos, Nuts and Bolts: Microfluidics for the Production of Biomaterials, Adv. Mater. Technol. 4 (2019) 1-21. doi:10.1002/admt.201800611.

[37] D. Van Swaay, A. Demello, Microfluidic methods for forming liposomes, Lab Chip. 13 (2013) 752-767. doi:10.1039/c2lc41121k.

[38] D. Liu, H. Zhang, F. Fontana, J.T. Hirvonen, H.A. Santos, Microfluidic-assisted fabrication of carriers for controlled drug delivery, Lab Chip. 17 (2017) 1856-1883. doi:10.1039/c7lc00242d.

[39] J. Ma, S.M.Y. Lee, C. Yi, C.W. Li, Controllable synthesis of functional nanoparticles by microfluidic platforms for biomedical applications-a review, Lab Chip. 17 (2017) 209-226. doi:10.1039/C6LC01049K.

[40] S. Abalde-Cela, P. Taladriz-Blanco, M.G. De Oliveira, C. Abell, Droplet microfluidics for the highly controlled synthesis of branched gold nanoparticles, Sci. Rep. 8 (2018) 1-6. doi:10.1038/s41598-018-20754-x.

[41] B. Herranz-Blanco, E. Ginestar, H. Zhang, J. Hirvonen, H.A. Santos, Microfluidics platform for glass capillaries and its application in droplet and nanoparticle fabrication, Int. J. Pharm. 516 (2017) 100-105. doi:10.1016/j.ijpharm.2016.11.024.

[42] J.P. Martins, G. Torrieri, H.A. Santos, The importance of microfluidics for the preparation of nanoparticles as advanced drug delivery systems, Expert Opin. Drug Deliv. (2018) 1-11. doi:10.1080/17425247.2018.1446936.

[43] D. Liu, S. Cito, Y. Zhang, C. Wang, T.M. Sikanen, H.A. Santos, A Versatile and Robust Microfl uidic Platform Toward High Throughput Synthesis of Homogeneous Nanoparticles with Tunable Properties, Adv. Mater. 27 (2015) 2298-2304. doi:10.1002/adma.201405408.

[44] D.L. and Y.P. Elisabeth Kastner, Varun Verma, Microfluidic- controlled 
manufacture of liposomes for the solubilisation of a poorly water soluble drug., Int. J. Pharm. 485 (2015) 122-130.

[45] A. Jahn, W.N. Vreeland, D.L. Devoe, L.E. Locascio, M. Gaitan, Microfluidic directed formation of liposomes of controlled size, Langmuir. 23 (2007) 6289-6293. doi:10.1021/1a070051a.

[46] G.T. Vladisavljevic, A. Laouini, C. Charcosset, H. Fessi, H.C.H. Bandulasena, R.G. Holdich, Production of liposomes using microengineered membrane and co-flow microfluidic device, Colloids Surfaces A Physicochem. Eng. Asp. 458 (2014) 168177. doi:10.1016/j.colsurfa.2014.03.016.

[47] V.M. Shah, D.X. Nguyen, P. Patel, B. Cote, A. Al-Fatease, Y. Pham, M.G. Huynh, Y. Woo, A.W. Alani, Liposomes produced by microfluidics and extrusion: A comparison for scale-up purposes, Nanomedicine Nanotechnology, Biol. Med. 18 (2019) 146-156. doi:10.1016/j.nano.2019.02.019.

[48] S. Joshi, M.T. Hussain, C.B. Roces, G. Anderluzzi, E. Kastner, S. Salmaso, D.J. Kirby, Y. Perrie, Microfluidics based manufacture of liposomes simultaneously entrapping hydrophilic and lipophilic drugs, Int. J. Pharm. 514 (2016) 160-168. doi:10.1016/j.ijpharm.2016.09.027.

[49] F. Bally, D.K. Garg, C.A. Serra, Y. Hoarau, N. Anton, C. Brochon, D. Parida, T. Vandamme, G. Hadziioannou, Improved size-tunable preparation of polymeric nanoparticles by microfluidic nanoprecipitation, Polymer (Guildf). 53 (2012) 50455051. doi:10.1016/j.polymer.2012.08.039.

[50] C. Costa, Z. Liu, J.P. Martins, A. Correia, P. Figueiredo, A. Rahikkala, W. Li, J. Seitsonen, J. Ruokolainen, S.-P. Hirvonen, A. Aguiar-Ricardo, M.L. Corvo, H.A. Santos, All-in-one microfluidic assembly of insulin-loaded $\mathrm{pH}$-responsive nano-inmicroparticles for oral insulin delivery, Biomater. Sci. (2020) 3270-3277. doi:10.1039/d0bm00743a.

[51] G. Rouser, S. Fleischer, A. Yamamoto, Two dimensional thin layer chromatographic separation of polar lipids and determination of phospholipids by phosphorus analysis of spots, Lipids. 5 (1970) 494-496. doi:10.1007/BF02531316.

[52] O.H. Lowry, N.J. Rosebrough, A. Lewis Farr, R.J. Randall, Protein measurement with the folin phenol reagent, J. Biol. Chem. 193 (1951) 265-275. 
[53] C.-S. Wang, R.L. Smith, Lowry Determination of Protein in the Presence of Triton X- 100, Anal. Biochem. 63 (1975) 414-417.

[54] R.W. Lange, D.R. Germolec, J.F. Foley, M.I. Luster, Antioxidants attenuate anthralin-induced skin inflammation in BALB/c mice: Role of specific proinflammatory cytokines, J. Leukoc. Biol. 64 (1998) 170-176. doi:10.1002/jlb.64.2.170.

[55] A. Ascenso, S. Pinho, C. Eleutério, F.G. Praça, M.V.L.B. Bentley, H. Oliveira, C. Santos, O. Silva, S. Simões, Lycopene from tomatoes: Vesicular nanocarrier formulations for dermal delivery, J. Agric. Food Chem. 61 (2013) 7284-7293. doi:10.1021/jf401368w.

[56] M.L.. Corvo, H.S.; Marinho, M.B.F. Martins, Nanomedicine as a strategy for the therapeutic use of Superoxide Dismutases, in: N.H. Philips (Ed.), Superoxide Dismutase (SOD), NOVA, 2016: p. 141. https://mail.google.com/mail/u/0/?pli=1\%5Cnpapers3://publication/uuid/D84FC782E317-4880-B951-0697213436E1.

[57] J.M. Zook, W.N. Vreeland, Effects of temperature, acyl chain length, and flow-rate ratio on liposome formation and size in a microfluidic hydrodynamic focusing device, Soft Matter. 6 (2010) 1352-1360. doi:10.1039/b923299k.

[58] R. Galovi Rengel, K. Bariši, E. Paveli, T. Ani Grubiši, I. Epelak, J. Filipovi-Grči, High efficiency entrapment of superoxide dismutase into mucoadhesive chitosancoated liposomes, Eur. J. Pharm. Sci. 15 (2002) 441-448. doi:10.1016/S09280987(02)00030-1.

[59] S. Simões, C. Marques, M.E. Cruz, M.B. Figueira Martins, Anti-inflammatory effects of locally applied enzyme-loaded ultradeformable vesicles on an acute cutaneous model, J. Microencapsul. 26 (2009) 649-658. doi:10.3109/02652040802630403.

[60] P. Marcelino, H.S. Marinho, M.C. Campos, A.R. Neves, C. Real, F.S. Fontes, A. Carvalho, G. Feio, M.B.F. Martins, M.L. Corvo, Therapeutic activity of superoxide dismutase-containing enzymosomes on rat liver ischaemia-reperfusion injury followed by magnetic resonance microscopy, Eur. J. Pharm. Sci. 109 (2017) 464471. doi:10.1016/j.ejps.2017.09.008. 
[61] A. Carvalho, M.B.F. Martins, M.L. Corvo, G. Feio, Enhanced contrast efficiency in MRI by PEGylated magnetoliposomes loaded with PEGylated SPION: Effect of SPION coating and micro-environment, Mater. Sci. Eng. C. 43 (2014) 521-526. doi:10.1016/j.msec.2014.07.055.

[62] T. Hernández- Caselles, J. Villalaín, J.C. Gómez- Fernández, Stability of Liposomes on Long Term Storage, J. Pharm. Pharmacol. 42 (1990) 397-400. doi:10.1111/j.2042-7158.1990.tb06578.x.

[63] J. Cauzzo, M. Nystad, A.M. Holsæter, P. Basnet, N. Škalko-Basnet, Following the fate of dye-containing liposomes in vitro, Int. J. Mol. Sci. 21 (2020) 1-17. doi:10.3390/ijms21144847.

[64] M.M. Gaspar, M.B. Martins, M.L. Corvo, M.E.M. Cruz, Design and characterization of enzymosomes with surface-exposed superoxide dismutase, Biochim. Biophys. Acta - Biomembr. 1609 (2003) 211-217. doi:10.1016/S0005-2736(02)00702-2.

[65] G. Liou, P. Storz, Reactive oxygen species in cancer, Free Radic. Res. 44 (2010) 479-496. doi:10.3109/10715761003667554.

[66] E.A. Hileman, G. Achanta, P. Huang, Superoxide dismutase: an emerging target for cancer therapeutics, Expert Opin. Ther. Targets. 5 (2001) 697-710.

[67] M.I. Adamczak, E. Hagesaether, G. Smistad, M. Hiorth, An in vitro study of mucoadhesion and biocompatibility of polymer coated liposomes on HT29-MTX mucus-producing cells, Int. J. Pharm. 498 (2016) 225-233.

doi:10.1016/j.ijpharm.2015.12.030.

[68] G.K. Srivastava, M.L. Alonso-Alonso, I. Fernandez-Bueno, M.T. Garcia-Gutierrez, F. Rull, J. Medina, R.M. Coco, J.C. Pastor, Comparison between direct contact and extract exposure methods for PFO cytotoxicity evaluation, Sci. Rep. 8 (2018) 1-9. doi:10.1038/s41598-018-19428-5.

[69] P. Marcelino, H.S. Marinho, M.C. Campos, A.R. Neves, C. Real, F.S. Fontes, A. Carvalho, G. Feio, M.B.F. Martins, M.L. Corvo, Therapeutic activity of superoxide dismutase-containing enzymosomes on rat liver ischaemia-reperfusion injury followed by magnetic resonance microscopy, Eur. J. Pharm. Sci. 109 (2017) 464471. doi:10.1016/j.ejps.2017.09.008.

[70] T.P. Pivetta, S. Simões, M.M. Araújo, T. Carvalho, C. Arruda, P.D. Marcato, 
Development of nanoparticles from natural lipids for topical delivery of thymol: Investigation of its anti-inflammatory properties, Colloids Surfaces B Biointerfaces. 164 (2018) 281-290. doi:10.1016/j.colsurfb.2018.01.053.

[71] M.M.A. Abdel-Mottaleb, B. Moulari, A. Beduneau, Y. Pellequer, A. Lamprecht, Nanoparticles enhance therapeutic outcome in inflamed skin therapy, Eur. J. Pharm. Biopharm. 82 (2012) 151-157. doi:10.1016/j.ejpb.2012.06.006.

[72] M.L. Corvo, H.S. Marinho, P. Marcelino, R.M. Lopes, C.A. Vale, C.R. Marques, L.C.D. Martins, P. Laverman, G. Storm, M.B.A.F. Martins, Superoxide dismutase enzymosomes: Carrier capacity optimization, in vivo behaviour and therapeutic activity, Pharm. Res. 32 (2015) 91-102. doi:10.1007/s11095-014-1447-7.

[73] Y. Nakamura, A. Mochida, P.L. Choyke, H. Kobayashi, Nanodrug Delivery: Is the Enhanced Permeability and Retention Effect Sufficient for Curing Cancer?, Bioconjug. Chem. 27 (2016) 2225-2238. doi:10.1021/acs.bioconjchem.6b00437.

[74] Y. Gao, X. Zhu, Y. Zhang, X. Chen, L. Wang, W. Feng, C. Huang, F. Li, In vivo biodistribution and passive accumulation of upconversion nanoparticles in colorectal cancer models via intraperitoneal injection, RSC Adv. 7 (2017) 31588-31596. doi:10.1039/c7ra04349j.

[75] P. Jacquet, P.H. Sugarbaker, Peritoneal-plasma barrier, Cancer Treat Res. 82 (1996) 53-63.

[76] T.M. Allen, C.B. Hansen, L.S.S. Guo, Subcutaneous administration of liposomes: a comparison with the intravenous and intraperitoneal routes of injection, BBA Biomembr. 1150 (1993) 9-16. doi:10.1016/0005-2736(93)90115-G. 